\begin{tabular}{|c|c|}
\hline \multirow{3}{*}{ 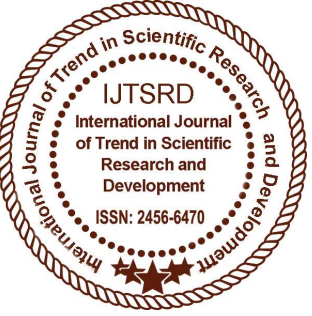 } & $\begin{array}{l}\text { International Journal of Trend in Scientific } \\
\text { Research and Development (IJTSRD) }\end{array}$ \\
\hline & International Open Access Journal \\
\hline & ISSN No: 2456 - 6470 | www.ijtsrd.com | Volume - 2 | Issue - 5 \\
\hline
\end{tabular}

\title{
Investigation of Structural and Thermal Properties of Nanostructured PANI
}

\author{
B. Sathish Mohan ${ }^{1}$, Y. Pavan Kumar ${ }^{1}$, D. Ramadevi ${ }^{2}$, K. Basavaiah ${ }^{3}$ \\ ${ }^{1,2}$ Research Scholar, ${ }^{3}$ Professor \\ ${ }^{1}$ Dept. of Inorganic \& Analytical Chemistry, ${ }^{2}$ AU College of Pharmaceutical Sciences, \\ ${ }^{3}$ Dept. of Inorganic and Analytical Chemistry, \\ Andhra University, Visakhapatnam, Andhra Pradesh, India
}

\section{ABSTRACT}

In this paper, we report a preparation of poly aniline (PANI) nanostructure by oxidative polymerisation in presence of $\mathrm{HCl}$ as do pant. The structural, morphological and thermal properties of as-prepared PANI was investigated by X-ray diffraction (XRD), Fourier transform infrared (FTIR), UV-Visible diffuse reflectance spectrophotometer (DRS), Field emission scanning electron microscopy (FESEM) and Thermo gravimetric analysis (TGA).It is found that the morphology of PANI is fibril like shape with band gap of $2.74 \mathrm{eV}$. Thermal conductivity of PANI nanostructure was calculated as a function of temperature.

Keywords: PANI, oxidative polymerisation and thermal conductivity.

\section{INTRODUCTION}

Intrinsic conducting polymers (ICPs) have been emerged as potential materials for many technological applications such as sensors, EMI shielding, electro chromic displays, batteries, energy storage, solar cells and catalysis [1-3]. Among all ICPs such as, polypyrrole, Poly (3,4-ethylenedioxythiophene),poly aniline (PANI) and its derivatives have received great attention due to their unique red ox chemistry and electrical properties, high chemical and environmental stability $[4,5]$.

The structure and properties of PANI are firmly connected to their synthetic methods, there are numerous methods like emulsion, micro-emulsion, diffusion polymerization and interfacial polymerization have been reported earlier [6-8].
Generally, each of these methods has its own advantages and limitations. To the best our knowledge, these synthetic methods can be broadly divided into two categories like chemical and electrochemical [9]. Chemical polymerization can result in various morphologies, like nanorods, nanospheres, nanofibers, nanotubes, nanoflakes, and nanoflowers $[10,11]$. This paper addresses the preparation of PANI nanofibrilsby chemical oxidative polymerization of aniline in aqueous medium using APS as oxidant and studies its structural and thermal properties.

\section{Experimental section}

\subsection{Materials and method}

Aniline $\left(\mathrm{C}_{6} \mathrm{H}_{7} \mathrm{~N}\right)$, hydrochloric acid $(\mathrm{HCl})$ and ammonium persulfate, APS $\left(\left(\mathrm{NH}_{4}\right)_{2} \mathrm{~S}_{2} \mathrm{O}_{8}\right)$ were procured from Sigma Aldrich. The Milli Q water used throughout the synthesis of PANI,

\subsection{Synthesis of PANI}

In typical synthesis, $0.1 \mathrm{M}$ of aniline was dissolved in $1 \mathrm{M} \mathrm{HCl}$ solution in a round bottom flask with constant stirring at $0-5^{\circ} \mathrm{C}$. Then an aqueous solution of APS $(0.1 \mathrm{M})$ was added drop wise to the reaction mixture under constant stirring for $4 \mathrm{~h}$. The reaction mixture is turned from pale blue colour to dark green colour, which indicates the formation of PANI. The reaction was further preceded for $12 \mathrm{~h}$ at $0-5{ }^{\circ} \mathrm{C}$. Then, the reaction mixture was allowed to attain room temperature. As formed green precipitate was centrifuged and washed periodically with water and method to remove the oligomers, unreacted in material. Then, finally dried under vacuum for $12 \mathrm{~h}$, 


\subsection{Characterisation}

The crystalline and phase formation of PANI was studied by X-ray diffraction (XRD, Bruker D8 Focus) with a $\mathrm{Cu} \mathrm{k}$ alpha radiation source with scan range of $2 \theta=10-70^{\circ}$ at a speed rate $0.02^{\circ}$ per step. The morphology of the PANI was characterized by scanning electron microscope (FESEM, JEOL field emission scanning electron microscope, JSM-6700F). The band gap was calculated by UV-Visible diffuse reflectance spectrophotometer (DRS, Shimadzu, $2700 \mathrm{R}$ ) in the range from 200 to $800 \mathrm{~nm}$. The rmogravimetricanalysis of PANI was carried out by TGA (TA instruments Q-500) in the temperature range of 30 to $700{ }^{\circ} \mathrm{C}$ with an air flow rate of $60 \mathrm{~m}$ $\mathrm{L} / \mathrm{min}$ and a heating rate of $10^{\circ} \mathrm{C} / \mathrm{min}$ under $\mathrm{Ar}$ atmosphere.

\section{Results and Discussion}

The XRD patterns of PANI were depicted in Figure 1(a). The characteristic diffraction peaks centred at
$2 \theta=14.5^{\circ}, 20^{\circ}, 25.9^{\circ}, 27.8^{\circ}$ which corresponds to parallel and perpendicular to phenyl rings of PANI, The XRD of PANI is in well agreement with the literature report [12].

The band gap energy of as-prepared PANI was calculated using UV-Visible DRS and the UV DRS spectrum was depicted in Figure1(b). The band gap of PANI was calculated from diffuse reflectance spectra by using equation 1 .

$\mathrm{E}_{\mathrm{g}}=\mathrm{h} \mathrm{v}=\mathrm{hc} / \lambda=1240 / \lambda$

Eq. (1)

Where $\mathrm{E}_{\mathrm{g}}$ is band gap energy, $\mathrm{h}$ is planks constant, $\mathrm{v}$ is wave frequency, $\mathrm{c}$ is light of speed and $\lambda$ is the wavelength. It can be found that the PANI has an absorption edge around $457 \mathrm{~nm}$ corresponds to the band gap of $2.74 \mathrm{eV}$.
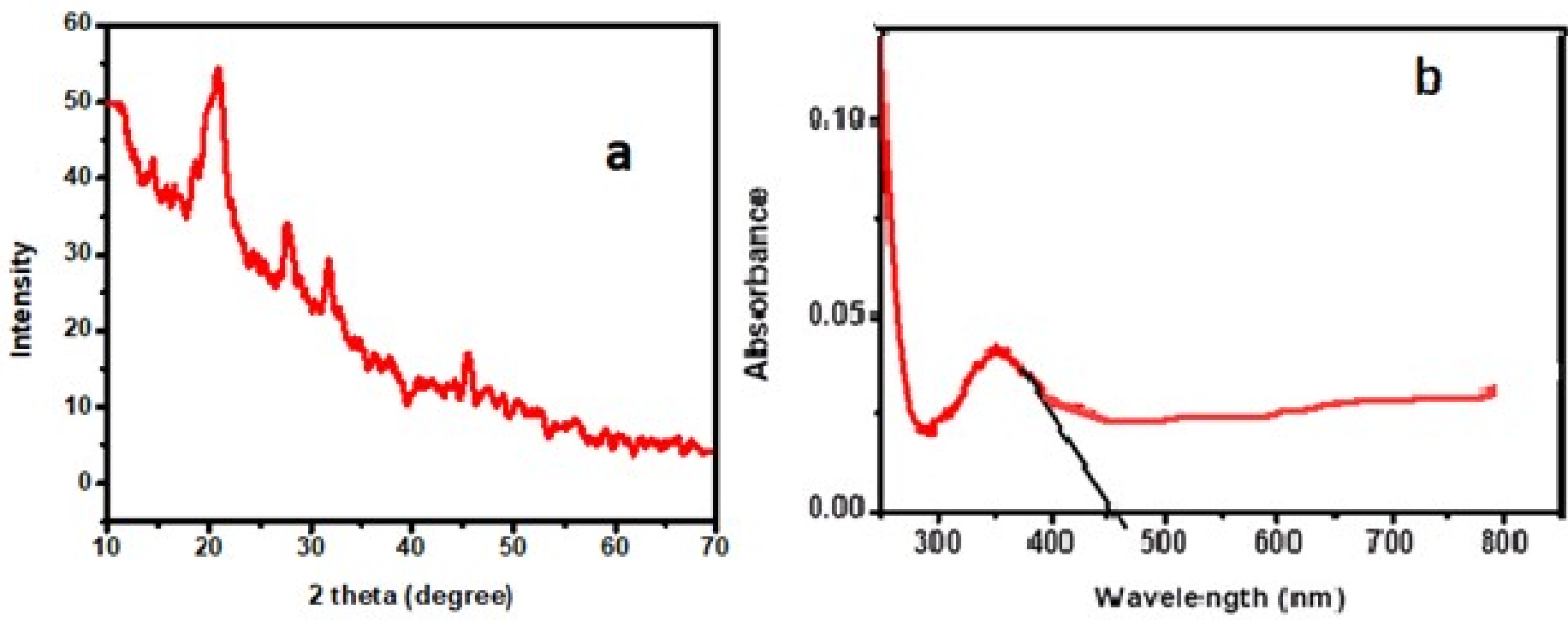

Figure 1: a) XRD patterns and b) UV DRS spectrum of PANI

FTIR spectrum of PANI is shown in Figure2. The characteristic peaks at 515 and $808 \mathrm{~cm}^{-1}$ were due to the presence of $\mathrm{C}-\mathrm{H}$ out-of planes bending vibrations and para-disubstituted benzene rings respectively [12]. The peak at $1307 \mathrm{~cm}^{-1}$ is ascribed to C-N stretching vibrations. The three characteristic peaks at 1154, 1491 and $1589 \mathrm{~cm}^{-1}$ are corresponds to in-plane bending vibrations in C-H, C-N and C-C respectively. A broad peak at $3403 \mathrm{~cm}^{-1}$ is associated to the presence of $\mathrm{N}-\mathrm{H}$ stretching of aromatic amines in PANI. 


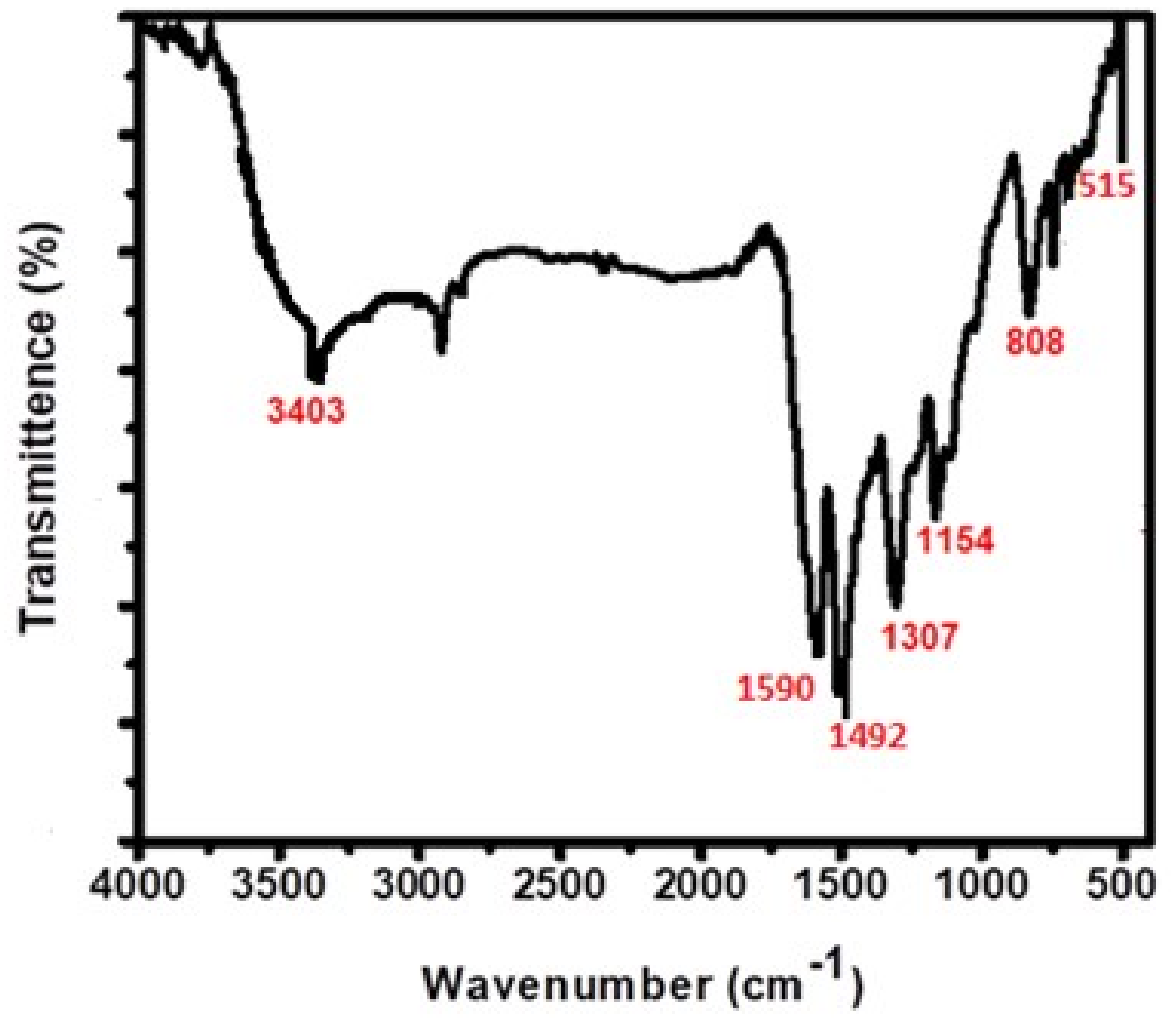

Figure 2: FTIR spectrum of PAN

The representative FESEM images of as-prepared PANI by chemical oxidative polymerization method were displayed in Fig. 3. The FESEM images clearly reveal the fibril like morphology.
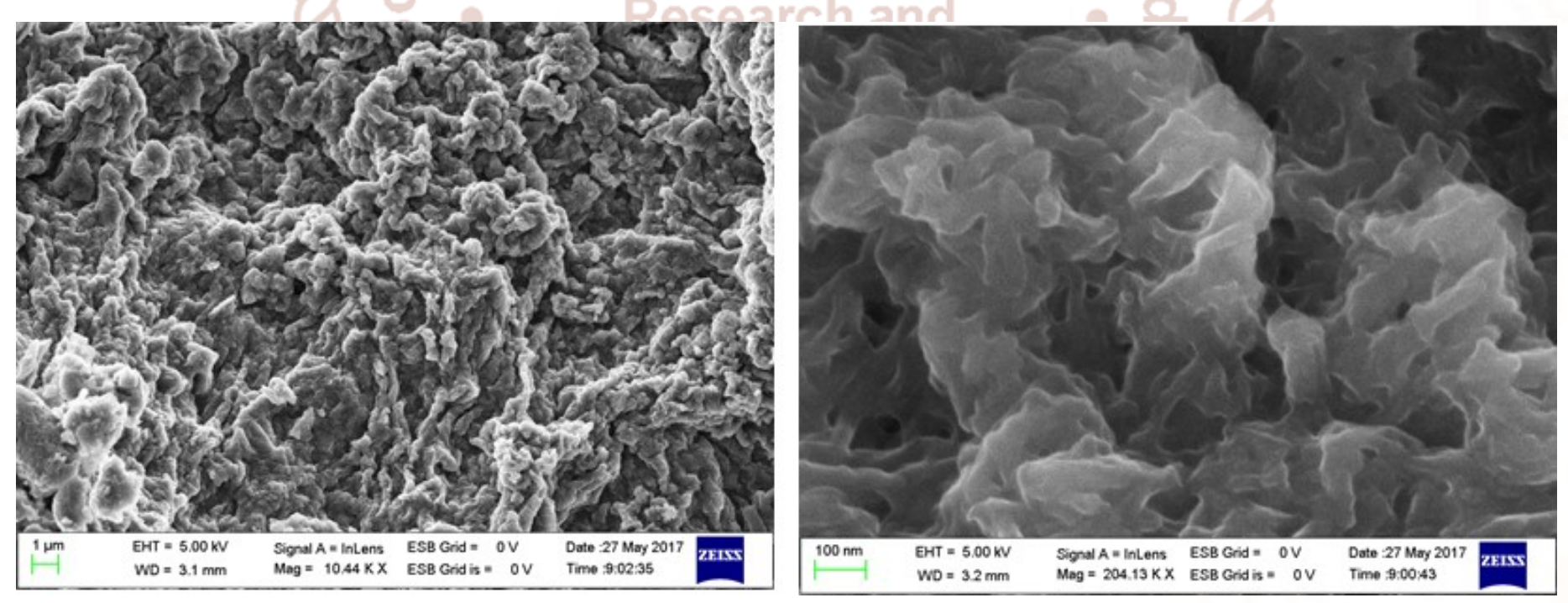

Figure 3: FESEM images of PANI

The TGA curve for PANI is presented in Fig. 4 (a). The TGA curve shows three characteristic weight losses at three different temperatures are 93,455 and $550{ }^{\circ} \mathrm{C}$. Figure $4 \mathrm{a}$ shows the thermal decomposition of PANI by weight loss percentage increases with the temperature. It shows a weight loss of $11.2 \%$ up to $93{ }^{\circ} \mathrm{C}, 19 \%$ from $94-455{ }^{\circ} \mathrm{C}$ and $49.4 \%$ from $455-550^{\circ} \mathrm{C}$ respectively due to loss of water molecules and reduces the benzeneoid rings [13-15]. 

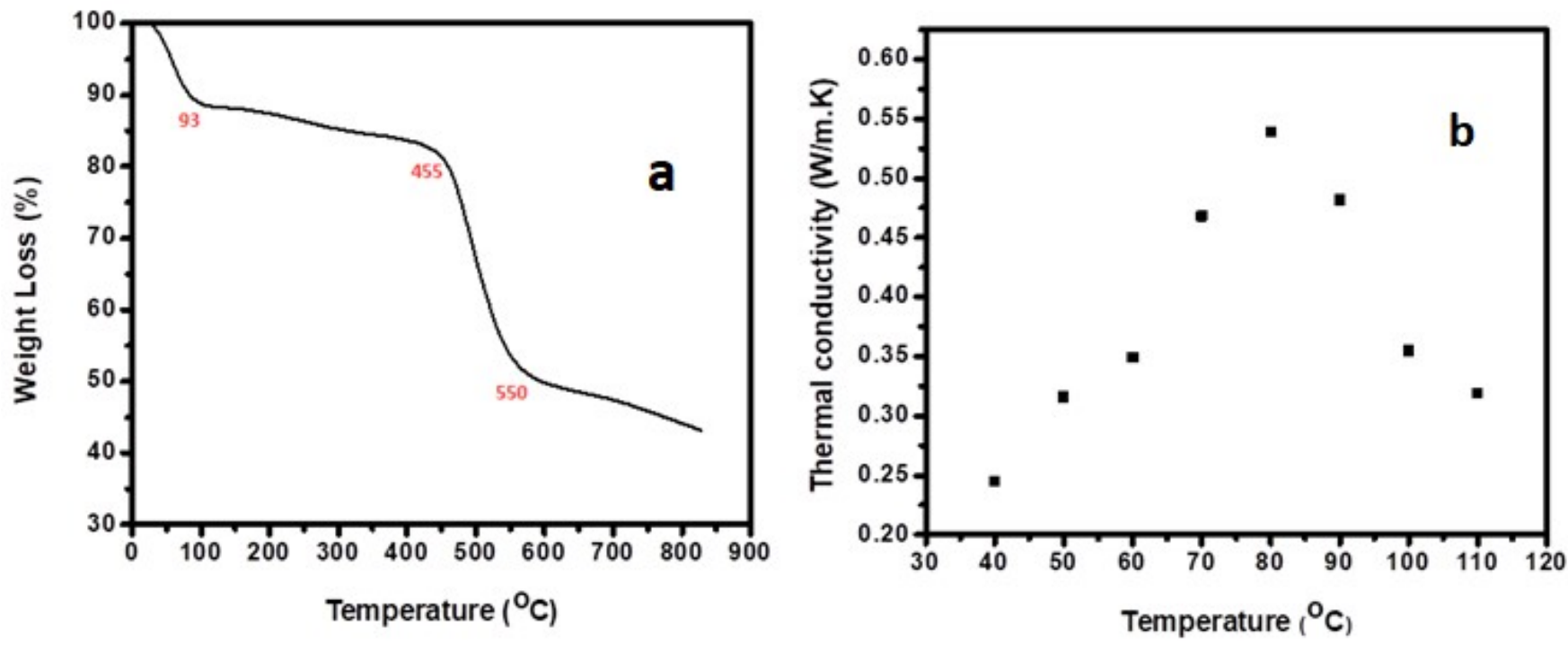

Figure 4: a) TGA curve an db) Thermal conductivity of PANI

The thermal conductivity of prepared PANI was measured using TA probe (Figure 4b). The temperature increases, thermal conductivity increases up to certain level and then decreases; this is due to the thermal conductivity is mostly depends on the motion of free electrons. As the temperature increases, the molecular vibrations increase (in turn decreasing the mean free path of molecules). Hence, they block the flow of free electrons, thus reducing the conductivity. The maximum thermal conductivity was shown at the temperature of $80{ }^{\circ} \mathrm{C}$ was shown in Table 1.

Table 1: Thermal conductivity of PANI at different temperatures

\begin{tabular}{|c|c|c|}
\hline $\begin{array}{c}\text { S. } \\
\text { No }\end{array}$ & $\begin{array}{c}\text { Temp } \\
\left({ }^{0} \mathrm{C}\right)\end{array}$ & $\begin{array}{c}\text { Thermal conductivity } \\
(\mathbf{W} / \mathbf{m} \text {. K })\end{array}$ \\
\hline 1 & 40 & 0.245 \\
\hline 2 & 50 & 0.316 \\
\hline 3 & 60 & 0.349 \\
\hline 4 & 70 & 0.468 \\
\hline 5 & 80 & 0.589 \\
\hline 6 & 90 & 0.482 \\
\hline 7 & 100 & 0.355 \\
\hline 8 & 110 & 0.319 \\
\hline
\end{tabular}

\section{Conclusion}

In summary, we have demonstrated a facile, reproducible method for the preparation of PANI nanofibrils via oxidative polymerization method using APS as an oxidant. The prepared PANI was characterized using XRD, FTIR, FESEM, UV-DRS and TGA to study its structural and thermal properties. The results clearly show that PANI has high thermal conductivity and hence it has thermal stability.

\section{Conflicts of Interest}

The authors clearly declared that there is no any conflict of interest.

\section{Acknowledgement}

The author, B. Sathish Mohan honour to acknowledge the University Grants Commission (UGC) for sponsoring the Rajiv Gandhi National Fellowship (RGNF-SC-AND-2016-17-9309).Also, I thankful to UGC-DRS-SAP-1 and DST-FIST in the Department of-Inorganic and Analytical Chemistry, Andhra University,

\section{References}

1. J. A. Conklin, S. C. Huang, S. M. Huang, T. Wan, R. B. Kaner, Thermal properties of poly aniline and poly(aniline-co-o-ethyl aniline),Macro mol., 28 (1995), 6522-6527.

2. L. Ding, X. Wang, R. V. Gregory, Thermal properties of chemically synthesized poly anilines (EB) powder, Synth. Met., 104 (1999), 73-78.

3. S. H. Goh, H. S. O. Chan, C. H. Ong, Miscible blends of conductive poly aniline with tertiary amide polymers, J. Appl. Polym. Sci. 68 (1998), 1839-1844.

4. S. Bhadra, D. Khastgir, N.K. Singha, J.H. Lee, Progress in preparation, processing and applications of poly aniline, Prog, Polym. Sci., 34 (2009), 783-810. 
5. C.H.Silva, N.A. Galiote, F. Huguenin, É. Teixeira M.L. Temperini, Spectroscopic, morphological and electro chromic characterization of layer-bylayer hybrid films of poly aniline and hexaniobatenanoscrolls, J. Mater. Chem., 22 (2012), 14052-14060.

6. Li XG, Zhou HJ, Huang MR., Synthesis and properties of a functional copolymer from N-ethyl aniline and aniline by an emulsion polymerization, Polymer. 46 (2005),1523-1533.

7. Huang K, Meng XH, Wan MX., Poly aniline hollow microspheres constructed with their own selfassembled nanofibers, J ApplPolym Sci. 100 (2006), 3050-3054.

8. Park SJ, Park SY, Cho AS, Choi HJ, Jhon MS., Synthesis and electro rheology of multi walled carbon nanotube /poly aniline nanoparticles, Synth Met. 152 (2005), 337-340.

9. D.W. Hatchett, M. Josowicz, J. Janata, Comparison of chemically and electrochemically synthesized poly aniline films, J. Electro hem. Soc., 146 (1999), 4535-4538.

10. C.A. Amarnath, J. Kim, K. Kim, J. Choi, D. Sohn, Nan flakes to nanorods and nanospheres transition of selenious acid doped poly aniline, Polymer, 49 (2008), 432-437.
11. H.D. Tran, J.M. D'Arcy, Y. Wang, P.J. Beltramo, V.A. Strong, R.B. Kaner, The oxidation of aniline to produce poly aniline: a process yielding many different nanoscale structures, J. Mater. Chem., 21 (2011), 3534-3550.

12. Palaniappan S and Amarnath C A, A novel poly aniline-maleic acid-dodecyl hydro gensulfate salt: soluble poly aniline powder React. Functional Polymers, 66 (2006), 1741-1748.

13. Chen S A, Chung K R, Chao C L and Lee H T, Synth Met, 82(1996), 207.

14. S. Wang, Z. Tan, Y. Li, L. Sun, T. Zhang, Synthesis, characterization and thermal analysis of poly aniline $/ \mathrm{ZrO}_{2}$ composites, Thermo him. Acta, 441(2006), 191-194.

15. C. G. Wu, Y. C. Liu, S. S. Hsu, Assembly of conducting polymer/metal oxide multilayer in one step, Synth. Met. 102 (1999), 1268-1269.

16. P. Xiao, M. Xiao, P. Liu, K. Gong, Direct synthesis of a poly aniline intercalated graphite oxide nanocomposite, Carbon, 38 (2000), 626628.



